\title{
Internal hydrophobization of cement mortar by addition of siloxanes
}

\author{
Kalina Grabowska ${ }^{1 *}$, Marcin Koniorczyk ${ }^{1}$ \\ ${ }^{1}$ Department of Building Physics and Building Materials, Lodz University of Technology, \\ Al.Politechniki 6, Łódź, 90-924, Poland
}

\begin{abstract}
Hydrophobic substances contain in its structure non-polar groups by which have the capability to "repel" water molecules. Because of them the material become hydrophobic, i.e. it is not water-wettable. Hydrophobic additives are used in various areas, including buildings, bridges, ceramic materials, underground constructions and marine constructions. The use of hydrophobic admixtures is one of the ways to protect building elements from adverse water effects, thereby increasing their durability by reducing the water absorption. In our study we investigated the influence of siloxanes on compressive strength and absorbability of cement mortar. The modification of cement mortar microstructure due to addition of organosilicon compounds was analyzed by mercury intrusion porosimetry. Finally we assessed the effectiveness of poly(dimethylsiloxane) and water solution of methyl silicon resin as hydrophobic admixture by measuring the water absorption coefficient.
\end{abstract}

\section{Introduction}

The impact of an aggressive external environment is one of the most frequent causes of degradation of building materials. The infiltration of water into the porous structure of the materials is one of the main factors leading to the deterioration of building elements. Water is responsible for inducing damage in building materials and is having a crucial influence on their durability. Water present in the pore structure may lead to frost damage, mold growth, salt crystallization, condensation, and decrease of thermal resistance. The parameter determining the influence of water on the porous material is its absorbability, i.e. the material's ability to absorb and retain water in the pore space. It is usually determined by the amount of water adsorbed by the material due to capillary forces. The material properties are significantly affected by the type of pores and their shape (from narrow gaps to spheroidal bubbles), their dimensions and distribution in the material. The majority of building materials are porous. Those based on Portland cement show not sufficient resistance to some physical and chemical impacts from the environment. This is the result of porous structure and susceptibility to the penetration of water. Water repellants are often applied to reduce the water infiltration. Addition of a hydrophobic admixture during the manufacturing process of building materials limits the water penetrating in entering the capillary voids and porous space [1-5] The first results on microstructure, capillary water

\footnotetext{
${ }^{*}$ Corresponding author: kalina.grabowska@edu.p.lodz.pl
} 
absorption, absorbability and mechanical properties on admixed cement mortar were received and are presented here.

\section{Materials}

A fundamental study was started to investigate the influence of two different organosilicon admixtures on cement mortar. Volume hydrophobization of cement mortar is carried out by adding of organic compounds to the batched water. The following admixtures were used as hydrophobic agents: the water solution of methyl silicon resin (MESI) and polydimethylsiloxane (PDMS). They were recommended by the manufacturer as very efficient water repellent admixtures to be applied in the fresh concrete or mortar. The Portland cement CEM I 32.5 was used in the whole study. Cement mortars were prepared according to PN-EN 196-1 with water to cement ratio (w/c) of 0.5 , addition of $1 \%, 2 \%$ or $3 \%$ of silicon-based agents per cement mass.

\section{Hydrophobization}

Hydrophobization is process of implementing the hydrophobic agents into the porous structure. As a result of a chemical reaction, its fills voids preventing or restricting the penetration of water or moisture. Aqueous or hydrocarbon solutions of organosilicon compounds are frequently used as the water-proofing admixtures. Hydrophobization provides to hydrophilic materials hydrophobic properties. The hydrophobicity or hydrophilicity of the material, i.e. the relative degree of water-surface interaction, can be determined by the wetting angle. Wetting angle is a measure of the hydrophilicity (hydrophobicity) of the material. For hydrophobic surfaces the wetting angle is above $90^{\circ}$. Hydrophobic admixtures can effectively reduce the capillary absorption improving the durability of the material. It's supposed to increase the surface tension at the interface between water and material, making it difficult to wipe. The aim of hydrophobization is to create a water-impermeable layer which does not affect the gas and water vapor diffusion. The main function of water repellents is to prevent water from penetration into the building materials. Hydrophobic admixtures should reduce water absorption, be UV stable and high alkalinity, be resistant to temperatures and other damaging external factors [1][2][6][7].

\section{Silicon-based admixtures}

Of all different kind of hydrophobic products organosilicon compounds such as silicone resins, silanes and siloxanes have proved to perform best in protecting building materials from water penetration and environmental influences. The starting point for all of these materials is silicon. Organosilicon admixtures contain chains and bonding networks between silicon and oxygen (-Si-O-Si-). The main structure of agents based on organosilicon compounds is polysiloxane chain (-O-Si-O-Si-O-). The type of substituents affects the diversity of spatial systems and on the hydrophobic properties. Generally silicon-based admixtures contain organic groups, predominantly methyl groups $\left(-\mathrm{CH}_{3}\right)$, which are bound to the silicon atom. Longer alkyl chain-length provides steric protection which make organosilicon agents unrepeatable in rendering building materials water repellent. The most important factor affecting the hydrophobization is size of molecules (siloxanes are oligomers with a molecular weight about 400-600, silicone resins and polysiloxanes molecular weight is about 2000-3000). The particle size of the organosilicon compounds affects the depth and speed of penetration into the structure of building materials. Silicone resins have the largest particles (about 100 times larger than the particles 
of siloxanes). The pore diameters decide on the possibility of a chemical compound adsorption[2][6][7].

\subsection{Poly(dimethylsiloxane)}

PDMS is a macromolecular organosilicon compound. There is a repetitive group with the generalized formula: $-\left[\mathrm{R}_{2} \mathrm{Si}-\mathrm{O}\right]$ - where $\mathrm{R}$ is the methyl group $-\mathrm{CH}_{3}$ in its structure. PDMS chains are flexible and arranged in helix. The methyl groups present in PDMS give a hydrophobic character and good anti-adhesive properties. PDMS are most widely used as fluids. Liquid form of PDMS is linear or cyclic polymer or resins depending on degree of polymerization and cross-linking [2][3].

\subsection{Water solution of methyl silicon resin}

Until recently the cheapest and widespread silicon-based agents used to surface hydrophobization were silicates, i.e. alkaline, aqueous solutions of sodium or potassium methylsilicate. Affected by $\mathrm{CO}_{2}$ its undergo a slow polymerization. As the molecule grows, the materials becomes hydrophobic. The process of hydrophobization is accelerating by $\mathrm{CO}_{2}$, and delays by calcium hydroxide. MESI is a strongly alkaline aqueous solution of methyl silicon resin. Its macromolecular organosilicon compound dissolved in potassium hydroxide[8].

a)<smiles>[R][Si]([R])([R])O[Si]([R])([R])O[Si]([R])([R])[R]</smiles>

Fig. 1. Structure of a) polysiloxane chain[2], b) poly(dimethylsiloxane), c) potassium methylsiliconate.

\section{Results}

\subsection{Mechanical tests}

Table 1 summarizes the results of mechanical properties received after 1, 2, 728 days for hydrophobized cement mortars. After 28 days ageing addition $1 \%$ and $2 \%$ of water solution of methyl silicon resin (MESI) caused measurably increase the compressive strength. Each number in Table 1 represents the average value taken over six samples. The addition 3\% MESI does not affect significantly the compressive strength. The addition of poly(dimethylsiloxane) (PDMS) decreases the mechanical properties by almost a factor of two after 28 days.

Table 1. Compressive strengths of cement mortars after 1, 2, 7 and 28 days of ageing.

\begin{tabular}{|c|c|c|c|c|c|}
\hline \multirow{2}{*}{$\begin{array}{c}\text { Water repellent } \\
\text { agent }\end{array}$} & \multirow{2}{*}{ Amount } & \multicolumn{4}{|c|}{ Compressive strengths [MPa] } \\
\cline { 3 - 6 } & & 1 day & 2 days & 7 days & 28 days \\
\hline Reference & $0 \%$ & 13,04 & 18,45 & 28,67 & 44,76 \\
\hline \multirow{3}{*}{ MESI } & $1 \%$ & 0,79 & 12,60 & 32,86 & 49,94 \\
\cline { 3 - 6 } & $2 \%$ & 1,81 & 14,09 & 30,23 & 46,83 \\
\cline { 2 - 6 } & $3 \%$ & 4,20 & 13,04 & 29,51 & 42,96 \\
\hline
\end{tabular}




\begin{tabular}{|l|c|c|c|c|c|}
\hline \multirow{3}{*}{ PDMS } & $1 \%$ & 5,03 & 8,76 & 10,47 & 25,84 \\
\cline { 2 - 6 } & $2 \%$ & 3,83 & 8,31 & 9,02 & 23,53 \\
\cline { 2 - 6 } & $3 \%$ & 3,65 & 9,07 & 11,91 & 22,16 \\
\hline
\end{tabular}

\subsection{Absorbability and capillary water absorption}

The effect of organosilicon admixtures on absorbability of cement mortars is shown in Table 2. They represents the average values taken over six samples. Addition of $1 \%$ or $2 \%$ of water solution of methyl silicon resin (MESI) and 3\% of poly(dimethylsiloxane) (PDMS) does not decrease significantly absorbability. The lowest value of absorbability was obtained for $2 \%$ of poly(dimethylsiloxane).

Table 2 summarizes capillary water absorption for hydrophobized cement mortars too. Results represents the average value taken over six samples. Addition of water solution of methyl silicon resin (MESI) does not decrease water absorption. The addition of poly(dimethylsiloxane) (PDMS) affect significantly the water absorption. Addition 3\% of PDMS reduce water absorption by half.

Table 2. Absorbability for cement mortars and capillary water absorption coefficient for cement mortar.

\begin{tabular}{|c|c|c|c|}
\hline $\begin{array}{c}\text { Water } \\
\text { repellent agent }\end{array}$ & Amount & $\begin{array}{c}\text { Absorbability } \\
{[\mathbf{\%}]}\end{array}$ & $\begin{array}{c}\text { Capillary water absorption } \\
\text { coefficient }\left[\frac{\mathbf{k g}}{\mathbf{m}^{\mathbf{2}} \mathbf{m i n}_{\mathbf{0}}^{\mathbf{0}} \mathbf{5}}\right]\end{array}$ \\
\hline \multirow{2}{*}{ Reference } & $0 \%$ & 7,6 & 0,21 \\
\hline \multirow{3}{*}{ MESI } & $1 \%$ & 7,4 & 0,25 \\
\cline { 2 - 4 } & $2 \%$ & 6,3 & 0,26 \\
\cline { 2 - 4 } & $3 \%$ & 4,9 & 0,26 \\
\hline \multirow{3}{*}{ PDMS } & $1 \%$ & 3,9 & 0,11 \\
\cline { 2 - 4 } & $2 \%$ & 2,3 & 0,11 \\
\cline { 2 - 4 } & $3 \%$ & 6,5 & 0,10 \\
\hline
\end{tabular}

\subsection{Mercury intrusion porosimetry}

The modification of cement mortar microstructure by addition of organosilicon admixtures is shown in Table 3. Addition of PDMS has led to increase pore diameter and decrease pore area.

Table 3. Results of porosimetric determinations.

\begin{tabular}{|c|c|c|c|}
\hline Sample & $\begin{array}{c}\text { Total Intrusion } \\
\text { Volume }\left[\frac{\mathbf{m l}}{\boldsymbol{g}}\right]\end{array}$ & $\begin{array}{c}\text { Total pore } \\
\text { area }\left[\frac{\mathbf{m}^{\mathbf{2}}}{\boldsymbol{g}}\right]\end{array}$ & $\begin{array}{c}\text { Average Pore } \\
\text { Diameter }[\mathbf{n m}]\end{array}$ \\
\hline Reference 0\% & 0,076 & 2,25 & 136,40 \\
\hline MESI 3\% & 0,077 & 2,27 & 136,80 \\
\hline PDMS 3\% & 0,085 & 1,14 & 297,40 \\
\hline
\end{tabular}




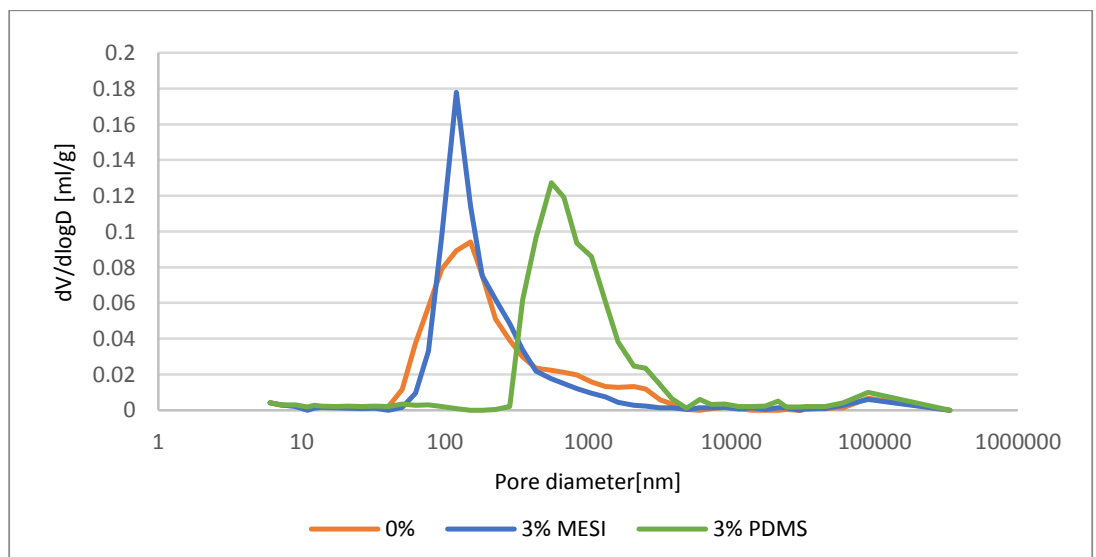

Fig. 2. Pore size distribution of cement mortars admixed 3\% of PDMS and 3\% of MESI.

\section{Conclusions}

The main objective of this paper is to investigate the influence of hydrophobic admixtures based on organosilicon compounds on physical properties of cement mortar. The use of poly(dimethylsiloxane) and water solution of methyl silicon resin as volume water repellent agents for cement mortar was analysed. We found out, that polysiloxane based agents provided better water repellent properties for cement mortar. It was found, that a volume hydrophobization by poly(dimethylsiloxane) had the desired effect of reduced capillary water absorption and absorbability. However PDMS drastically decline compressive strength compared to MESI where slight strengthening is noted. The impact of PDMS and MESI on absorbability is observed independently of the amount of used admixture. The lowest value of absorbability was obtained for $2 \%$ of poly(dimethylsiloxane). Only PDMS decreased capillary water absorption coefficient. The amount of used hydrophobic admixture had no significant effect on capillary water absorption. Addition of $1 \%$ and $2 \%$ of PDMS and 3\% MESI substantially reduce absorbability. Increase of pore diameter was observed for poly(dimethylsiloxane). Organosilicon agents (PDMS and MESI) should react with the cement phases $\left(\mathrm{C}_{3} \mathrm{~S}, \mathrm{C}_{2} \mathrm{~S}, \mathrm{C}_{3} \mathrm{~A}\right.$ or $\left.\mathrm{CSH}\right)$ making cement materials hydrophobic. PDMS react with $\mathrm{C}_{3} \mathrm{~A}$ phase which affects mechanical properties. If the water solution of methyl silicon resin was used the effect of hydrophobization is not clearly. As it was mentioned earlier, the reaction of polymerization of MESI occurs by $\mathrm{CO}_{2}$, which is not available in the cement mortar. It result in ineffectiveness of volume hydrophobization.

As a conclusion, it can be said that poly(dimethylsiloxane) as hydrophobic admixture is efficient additives for cement mortar. But in our opinion this problem still requires more studies.

\section{References}

1. W. Kurdowski, Chemia cementu i betonu (PWN, Warszawa, 2010)

2. D. Barnat-Hunek, Swobodna energia powierzchniowa jako czynnik ksztattujacy skuteczność hydrofobizacji $w$ ochronie konstrukcji budowlanych (Politechnika Lubelska, Lublin, 2016)

3. V. Spaeth, M.P. Delplancke-Ogletree and J.P. Lecomte, Hydrophobe V Aedificatio Publisher, 245 (2008) 
4. G. Wypych, Handbook of Surface Improvement and Modification (ChemTec Publishing, Toronto, 2018)

5. M. Najduchowska, P. Pichniarczyk, CEM WAPNO BETON, 3, 141 (2010).

6. M. Roos, F. König, S. Stadtmüller, B. Weyershausen, Hydrophobe V Aedificatio Publishers, 3 (2008)

7. S. Fic, D. Barnat-Hunek, Int. J. Mater. Sci. Eng, 2, 93 (2014)

8. T. Szymura, Chemia w inżynierii materiatów (Politechnika Lubelska, Lublin, 2015) 